\title{
Conf-7roleol--3 $000-3084-46$
}

\author{
Division of Engineexing \\ Brown University \\ Providence, P.I.
}

POROUS RIGID-PLASTIC MATERIALS CONTAINING -RTGID INCLUSIONS -

YIELD FUNCTION, PLASTIC POTENTIAL, AND VOID NUCLEATION

Arthur L. Gurson

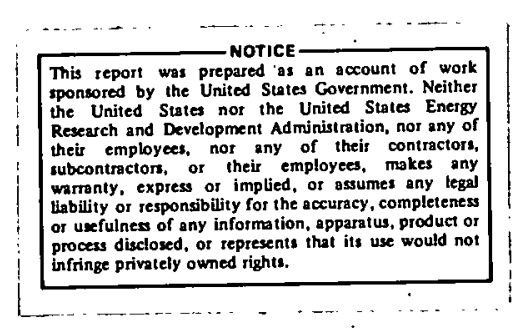

U.S. Energy Research and Development Commission

Contract E(11-1)-3084

Technica.l Report No. 46

$E(11-1)-3084 / 46$

July 1976

DISTRIBUTION OF THIS DOCLNEANT IS UNEIMITEO 


\section{DISCLAIMER}

This report was prepared as an account of work sponsored by an agency of the United States Government. Neither the United States Government nor any agency Thereof, nor any of their employees, makes any warranty, express or implied, or assumes any legal liability or responsibility for the accuracy, completeness, or usefulness of any information, apparatus, product, or process disclosed, or represents that its use would not infringe privately owned rights. Reference herein to any specific commercial product, process, or service by trade name, trademark, manufacturer, or otherwise does not necessarily constitute or imply its endorsement, recommendation, or favoring by the United States Government or any agency thereof. The views and opinions of authors expressed herein do not necessarily state or reflect those of the United States Government or any agency thereof. 


\section{DISCLAIMER}

Portions of this document may be illegible in electronic image products. Images are produced from the best available original document. 
Arthur L. Gurson ${ }^{1}$

\section{INTRODUCTION}

Development of theories of ductile fracture require constitutive relations which show details of material behavior. Engineering materials frequently are aggregates of several phases of widely varying properties, making the constitutj.ve behavior of an aggregate more complex than that of any of the individual phases. In this paper, the effect on constitutive behavior of the presence of rigid particles, embedded in and bonded to a rigid-plastic porous matrix, is examined. It is shown that the yield function is altered, and that the familiar concept of the yield function as a plastic potential must be used more carefully. The results also show how a void nucleation mechanism could destabilize, causing rapid bulk softening and failure $[1,3]$.

\section{YIELD FUNCTION AND PLASTIC POTENTIAL}

Strictly speaking, a yield function defines a locus of points in stress space for which a body, at a certain state of plastic deformation, will attain plastic yield. A plastic potential is a function of stress (at yield) which gives the direction of plastic flow via normality. In the conventional theory of rigid-plastic flow, the yield function $\Phi$ is used as a plastic potential [2]:

$$
\dot{\underline{\varepsilon}}=\Lambda \frac{\partial \Phi}{\partial \underline{\underline{g}}},
$$

where $g$ is the microscopic (pointwise) stress tensor, $\underline{f}$ is the microscopic deformation rate tensor, and $\Lambda$ is a scalar multiplier determined from boundary conditions or hardening data. It can be shown $[3,4]$ that this concept carries over to macroscopic measures of stress ( $\Sigma$ ) and deformation rate (E) in a wide class of porous rigid-plastic materials:

$$
\underline{\dot{E}}=\Lambda \frac{\partial}{\partial \underline{\Sigma}}\left[\Phi\left(\sigma_{y}, \underline{\Sigma}, f\right)\right] \text {, }
$$

where $\sigma_{y}$, the equivalent tensile flow stress of the matrix, is assumed (for simplicity) to be uniform. The theory which led to Eq. (2) will be extended here to include the effects of void nucleation at rigid particles embedded in the matrix. Special attention is paid to a modification of the stress-dependent nucleation criterion developed by Argon, et al. [6].

Consider the general case of a rigid, work hardening ductile matrix containing both voids and rigid particles, the latter debonding from the matrix when some critical stress is reached at the particlematrix interface. One can then write the general expression

$$
d f=d f(\text { nucl. })+d f(\text { growth }) \equiv b_{i j} d \Sigma_{i j}+b^{f} d \Lambda .
$$

\footnotetext{
1. Structures Dept., Avco Systems Div., Wilmington, Mass., U.S.A. .
} 
is is void volume fraction; d indicates an increment, and $b_{i j}$. and $b_{3}$ are differential coefficients. df (nucl.) is the part of df due to void nucleation at rigid particles; df (growth) is the part of df due to void growth, and is related to macroscopic plastic dilatancy. (See Eq. (22).) Consider also a yield function for this material, approximated as dependent on $f ., \sigma_{y}$, and the first two invariants of $\underline{\Sigma}$ :

$$
\begin{aligned}
& \Phi=\Phi\left(\Sigma_{\text {eqv }}, \Sigma_{H}, \sigma_{y}, f\right)=0, \\
& \Sigma_{H}=\frac{1}{3} \Sigma_{k k}, \Sigma_{i j}^{\prime}=\Sigma_{i j}-\Sigma_{H} \delta_{i j}, \Sigma_{e q v}=\left(\frac{3}{2} \Sigma_{i j}^{\prime} \Sigma_{i j}^{\prime}\right)^{1 / 2}
\end{aligned}
$$

(Figure 1 contains a schematic of this type of yield function; specific examples were developed in refs. $[3,4]$. One is shown in Eq. (11).) It is a reasonable approximation to limit the stress dependence of $\mathrm{df}$ to the first two invariants of stress also:

$$
d f=b_{1}^{f} d \Sigma_{e q v}+b f_{2}^{f} d \Sigma_{H}+b f_{3} d \Lambda \text {, }
$$

where $b_{i} f_{i}=1,3$ are differential coefficients. For a work hardening material, one may write

$$
\mathrm{d} \sigma_{\mathrm{y}}=\frac{\mathrm{d} \sigma_{\mathrm{y}}}{\mathrm{d} \Lambda} \overline{\mathrm{d}} \Lambda
$$

Now, using Eqs. (4) and (5) and applying consistency to the yield function (commas denote partial differentiation):

$$
\begin{aligned}
\delta \Phi=0 & =\left(\Phi, \Sigma_{\text {eqv }}+\Phi, b_{1}^{f}\right) d \Sigma_{e q v}+\left(\Phi, \Sigma_{H}+\Phi, b_{2}^{f}\right) d \Sigma_{H} \\
& +\left(\Phi, \sigma_{y} \sigma_{y, \Lambda}+\Phi, f b_{3}^{f}\right) d \Lambda .
\end{aligned}
$$

When moving along the yield function of a work hardening material, no plastic flow takes place, so $d \Lambda=0$. Equation 7 ther gives the tangent to the yield function as

$$
\frac{d \Sigma_{e q v}}{d \Sigma_{H}}=-\frac{\left(\Phi, \Sigma_{H}+\Phi, f b_{2}^{f}\right)}{\left(\Phi, \Sigma_{e q v}+\Phi, f b_{1}^{f}\right)}
$$

Using the derivation of a flow rule in refs. [3, 4], and assuming that void nucleation affects only the rate of change of $\dot{\underline{\epsilon}}$ and not $\dot{\dot{\epsilon}}$ itself, it can be shown that the plastic potential is equivalent to the yield function with nucleation ignored. The tangent to the plastic potential is thus

$$
\frac{d \Sigma_{\text {eqv }}}{d \Sigma_{H}}=-\frac{\Phi, \Sigma_{H}}{\Phi, \Sigma_{\text {eqv }}}
$$

Thus, with nucleation as a mechanism for increasing $f$, the yield function is no longer strictly equivalent to a plastic potential.

bel.ow)

In a specific form of Eq. (5) (developed in [3] and discussed

$$
b_{1}^{f}=0, \quad b_{2}^{f}=0 \text { if } d \Sigma_{H}<0, b{ }_{2}>0 \text { if } d \Sigma_{H}>0
$$


Nucleation (the breaking of a matrix-particle bond) is considered.irreversible, and cannot take place when the increment of hydrostatic stress is negative.

In $[3,4]$, specific forms of the yield function were developed which did not take nucleation into account. These can be used to calculate the derivatives in Eqs. (8) and (9). An example is given below; it is an upper bound yield function for a ductile matrix containing spherical voids; with the assumptions of a fully plastic flow field in the matrix (upper bound calculation), and uniform $\sigma_{\mathrm{y}}$ :

$$
\Phi=\frac{\Sigma_{e q v^{2}}}{\sigma_{y}^{2}}+2 f \cosh \left(\frac{3}{2} \frac{\Sigma_{H}}{\sigma_{y}}\right)-1-f^{2}=0
$$

The following are true for Eq. (11), and are reasonable to expect from any other forms of $\Phi$ :

$$
\Phi, f>0, \Phi, \Sigma_{\text {eqv }}>0 \text {, and } \Phi, \Sigma_{H}>0 \text { for } \Sigma_{H}>0
$$

Using Eqs. (10) and (12) in Eq. (8), the slope of the yield function is shown to be equal to $\left(d \Sigma_{H}<0\right)$ or more negative than $\left(d \Sigma_{H}>0\right)$ that of the plastic potentia1. Thus, given a state of yield in stress space, the yield surface vill lie on or inside the plastic potential. (See figure 1.) Only the portion of the yield function for which $d \Sigma_{H}<0$ can be used as a plastic potential.

\section{NUCLEATION CRITERIA}

Two specific void nucleation criteria were investigated in [3], and will be outlined here. The first, based on the experimental work of Gurland [5] on particle cracking in spheroidized $1.05 \%$ carbon steel, favors a criterion based on the strain increment. When a cracked particle is presumed to behave like a void of equal size, and $f_{u p}$ is the volume fraction of unbroken particles, the criterion is

$$
\mathrm{df}(\text { nucl }) \cong C_{1}^{*} f_{\text {up }} d \bar{E} \text {, where } \bar{E}=\left(\frac{2}{3} E_{i j}^{\prime} E_{i j}^{\prime}\right)^{1 / 2}
$$

$\mathrm{C}_{1}^{*}$ is a material constant calculated from the experimental data; Gurland's data gave $C_{1}^{*}=0.29$.

The second criterion is based on the work of Argon et a1. [6], who favor a critical normal interfacial (matrix-particle) stress condition for nucleation. Their calculations show that for a single rigid particle, embedded in an infinite matrix undergoing plastic flow under pure shear stress, the normal interfacial stress is very close to $\sigma_{y}$ in the matrix. (Note: here, $\sigma_{y}$ is the current value, increased by work hardening.) They also study the stress amplifying effect of a second particle in close proximity to the first. Based on their work, the following form is suggested [3]:

$$
\sigma_{i}=M(c) \sigma_{y}+\frac{\Sigma_{H}}{1-f}
$$

$M(c)$ is a stress amplification factor (a function of the local particle concentration $c$ ), and $\sigma_{i}$ is the normal interfacial stress. The final term represents, in an approxinate way, the microscopic tensile stress at the interface due to $\Sigma_{H}$. Matrix-particle separation (void nucleation) results 
when $\sigma_{\mathrm{i}}$ reaches $\sigma_{i}{ }^{\mathrm{c}}$, the critical value. (Note: ref. [7] shows that $\sigma_{y}{ }^{*} \leq \sigma_{i}{ }^{c} \leq 6 \sigma_{y}{ }^{*}$, where $\sigma_{y}{ }^{*}$ is the initial tensile yield stress of the matrix, is a reasonable range of values for engineering materials.) $M(c)$ is calculated as the ratio of upper bound values of the interfacial stress for interacting particles with local concentration $c$ to the upper bound stress when no interaction takes place. Calculations of the upper bound stresses were based on [6], as modified in [3]. (In [3], the plastic drag $\left(k_{s}\right)$ at a displacement incompatibility is a work hardening quantity; in [6], it is a material constant.) Curves of $M(c)$ versus $c$ are shown in fig. 2 for various values of $n$, the matrix hardening exponent.

Define $c^{*}$ as the value of $c$ at which $\sigma_{i}{ }^{c}$ is reached (Eq. (14)). A statistical calculation is done in [6], resulting in the fraction of randomly distributed particles which are in local concentration of $c^{*}$ or more. Assuming that a separated particle behaves like a void of equal volume, the following incremental form results (via Leibnitz's rule for differentiation of definite integrals).

$$
\mathrm{df}(\text { nucl. })=-\frac{0.4412}{\Gamma\left(\frac{\mathrm{c}^{*}}{\bar{c}}+1\right)} \mathrm{dc}^{*},
$$

where $\Gamma$ is the Gamma function and $\bar{c}$ is the volume average of $\bar{c} \cdot c^{*}$ decreases as $\sigma_{y}$, the average hardening state of the matrix, increases. (See Eq. (14) with $\sigma_{i}=\sigma_{i}^{c}$, and fig. 2.) Increments in $\sigma_{y}$ can be estimated from the macroscopic behavior of the material, the curxent state, and the matrix properties:

$$
\left.: \mathrm{d} \bar{\epsilon}=\frac{\Sigma_{\mathrm{ij}} \mathrm{d} E_{\mathrm{ij}}}{\sigma_{\mathrm{y}}(1-\mathrm{f})}, \mathrm{d} \sigma_{\mathrm{y}}=\frac{\mathrm{d}}{\mathrm{d} \bar{\epsilon}}\left(\sigma_{\mathrm{y}}(\bar{\epsilon})\right)^{*} \mathrm{~d} \bar{\epsilon}, \bar{\epsilon}=\left(\frac{2}{3} \epsilon_{\mathrm{ij}}^{\prime} \epsilon^{\prime}\right)^{1 \mathrm{j}}\right)^{1 / 2}
$$

Given $\mathrm{d} \sigma_{\mathrm{y}}$, dc* can be calculated numerically from Eq. (14), where $\sigma_{\mathrm{i}}$ is kept constant at $\sigma_{i}^{c}$ :

$$
d\left(\sigma_{i} c\right)=0 i=\left.\frac{d M}{d c}\right|_{c^{*}} \cdot \sigma_{y} d c^{*}+M\left(c^{*}\right) d \sigma_{y}+d\left(\frac{\Sigma_{H}}{1-f}\right)
$$

The last term above must be expanded in detail. Using the nondimensional macroscopic stress $\underline{S}$, where

$$
\underline{S} \equiv \underline{\Sigma} / \sigma_{y}
$$

the chain rule gives

$$
\mathrm{d}\left(\frac{\Sigma_{\mathrm{H}}}{1-\mathrm{f}}\right)=\frac{\mathrm{S}_{\mathrm{H}}}{(1-\mathrm{f})} \cdot \mathrm{d} \sigma_{\mathrm{y}}+\frac{\sigma_{\mathrm{y}}}{1-\mathrm{f}} \cdot \mathrm{d} \mathrm{S}_{\mathrm{H}}+\frac{\sigma_{\mathrm{y}} \mathrm{S}_{\mathrm{H}}}{(1-f)^{2}} \cdot \mathrm{df}
$$

Given enough information about a particular problem, $\mathrm{dS}_{\mathrm{H}}$ can be put in terms of df. Then, Eq. (17) can be written as

$$
\begin{aligned}
& -\frac{d M}{d c^{*}} \cdot \frac{\Gamma\left(c^{*} / \bar{c}+1\right)}{0.4412} \cdot d f(\text { nucl })+\frac{\sigma_{y}}{1-f}\left(\frac{d S_{H}}{d f}+\frac{S_{H}}{1-f}\right)(d f(\text { rucl })+d f(\text { groweth }) \\
& +M\left(c^{*}\right) d \sigma_{y}=0
\end{aligned}
$$

$d \sigma_{y}$ and $d f(g r o w t h)$ are both linear functions of the flow parameter. (See Eqs. (1), (16), and (22).) Rearranging terns gives 


$$
\mathrm{df}(\text { nucl })=\left[\frac{\mathrm{d} M}{\mathrm{dc} c^{*}} \frac{\Gamma\left(c^{*} / \bar{c}+1\right)}{0.4412}-\frac{\sigma_{\mathrm{y}}}{1-\mathrm{f}}\left(\frac{\mathrm{d} \mathrm{S}_{\mathrm{H}}}{\mathrm{df}}+\frac{\mathrm{S}_{\mathrm{H}}}{\overline{1-f}}\right)\right]=(\ldots) \mathrm{d} \Lambda
$$

NUCLEATION INSTABILITY

Nucleation becomes unstable if the coefficient of df(nucl..) goes to zero. The burst of nucleation would cause instantaneous bulk softening, which under the proper circumstances $[1,3]$ could lead to an unstable macroscopic flow field bifurcation (ductile fracture). Note that unstable nucleation of the type suggested in Eq. (21) could not occur given the flow dependent nucleation mechanism of Eq. (13). (A similar type of instability, corresponding to a macroscopic non-hardening state $[1,3]$, could still occur.)

$\mathrm{df}$ (growth) can be expressed in terms of $\mathrm{d} \underline{\mathrm{E}}$ as follows:

$$
\mathrm{df}(\text { growth })=(1-f) \mathrm{dE}_{\mathrm{kk},}=(1-f) \Phi, \Sigma_{k \mathrm{k}} \mathrm{d} \Lambda
$$

In fig. 3, this is compared to df(nucl.) over a range of matrix hardening levels, for several values of $\sigma_{i}{ }^{c}$. The instability suggested in Eq. (21) is quite evident. $\Phi$ as used in the calculation of these curves was derived in $[3,4]$ for a long circular cylindrical void geometry. The form is similar to Eq. (11). Note that quantities on the vertical axis are normalized by $f$ and $\bar{c}$.

The effect of nucleation on the slope of the yield function can be seen from fig. 4, for a specific case of Eq. (11). Note that here, $\sigma_{i}{ }^{c}$ is normalized by $\sigma_{y}$, the current state of matrix hardening. As $\Sigma_{H}$ increases, the value of $M\left(c^{*}\right)$ (and thus $c^{*}$ ) needed to attain nucleation decreases, until $M\left(c^{*}\right) \rightarrow 1$ and nucleation takes place at all particles not yet debonded from the matrix. df(nucl.), as calculated in Eq. (21), again becomes unstable. When this happens, $b_{2}$ in Eq. ( 8 ) becomes infinite and the slope of the yield function becomes negative infinite, as suggested in the figure.

\section{ACKNOWL.EDGEMENT}

The author gratefully acknowledges the financial support of the Energy Research and Development Agency, under Contract E(11-1)-3084, during the course of the work leading to this paper.

The work is based on part of the author's Ph.D. thesis (1975, Brown University). The contribution of the thesis advisor, Prof. J. R. Rice, is also gratefully acknowledged.

\section{REFERENCES}

1. BERG, C. A., "Ductile Fracture by Development of Surfaces of Unstable Cavity Expansion", Journal of Research of N.B.S., 76C, nos. 1 and 2, $1972,33-39$.

RUDNTCKI, J. W., and RICE, J. R., "Conditions for Localization of Deformation in Pressure-Sensitive Dilatant Materials", J. Mech. Phys. Solids, 23, 1975, 371-394.

2. HILL, R., The Mathematical Theory of Plasticity, The University Press, Oxford, 1950 .

3. GURSON, A. L., "Plastic Flow and Fracture Behavior of Ductile Materials Incorporating Void Nucleation, Growth, and Interaction", Ph.D. Thesis, Div. of Engineering, Brown Univ., Providence, R.I., 1975. 
4. GURSON, A. L., "Continuum Theory of Ductile Rupture by Void Nucle-altion and Growth: Part 1 - Yield Criteria and Flow Rules for Porous Ductile Media" to appear in Trans. A.S.M.E., J. Engin. Mat. Tech, 1976.

5. GURLAND, J., "Observations on the Fracture of Cementite Particles in a Spheroidized 1.05\% C Steel Deformed at Room Temperature", Acta Meta1lurgica, 20, 1972, 735-741.

6. ARGON, A. S., IM, J., and SAFOGLU, R., "Cavity Formation from Inclusions in Ductile Fracture", Metallurgical Transactions 6A, 1975, 825-837.

7. EASTERLING, K. E., FISCHMEISTER, H. F., and NAVARA, E., "The Particleto-Matrix Bond in Dispersion-Hardened Austenitic and Ferritic Iron Alloys", Powder Metallurgy 16, 1973, 128-145. 
